MATEC Web of Conferences 3, 01073 (2013)

DOI: $10.1051 /$ matecconf/20130301073

C) Owned by the authors, published by EDP Sciences, 2013

\title{
Prediction of the permeability of polymers to gases and condensable vapors
}

\author{
M. Kréa, H. Hasnaoui, N. Terkmane, and L.Gheraba \\ Laboratoire Matériaux et Environnement, Université de Médéa Route Ain d’Heb 26000, Médéa Algérie
}

In recent decades, a considerable number of studies on the permeation of polymer films to gases has been achieved. Often, these studies are oriented towards finding a close relationship between the permeability parameters and microstructure of the membrane forming material candidate for separation / recovery of gases or condensable vapors [1]. This has resulted in a very large accumulated experimental data of permeation parameters (coefficients of permeability, diffusivity and solubility, activation energy, etc...) of gases through films or membrane polymers [2].

It is very interesting to use these data in the development of prediction rules of permeation parameters for polymers that have not been yet investigated or even in the synthesis of new membrane forming materials. These rules, if they are well made, would facilitate and greatly simplify the synthesis of new membrane materials with improved properties for any target separation [3-5].

This work is a contribution to the prediction of the permeability of a polymeric film to permanent gases (N2, $\left.\mathrm{O}_{2}, \mathrm{H}_{2}\right)$ and condensable vapors $\left(\mathrm{CO}_{2}\right.$ and volatile hydrocarbons). It consist to collect and develop models that predict the permeability coefficient $(\mathrm{Pe})$ and in particular, the solubility coefficient (S) polymer films with condensable vapors. The results of these predictive models will then be subject to a comparison with experimental results for different classes of polymeric materials.

\section{References}

1. Y. Hirayama et al., J. Membr. Sci. 111169 (1996)

2. Materials Science of Membranes for Gas and Vapor Separation, Ed: Y. Yampolskii, I. Pinnau and B.D. Freeman, John Wiley \& Sons, England (2006)

3. M. Salame, Polym. Eng. Sci. 26 (1986)

4. J.Y. Park, D.R.Paul, J. Membr. Sci. 12523 (1997)

5. Y. Yumpolskii et al., J. Membr. Sci. 149203 (1998) 